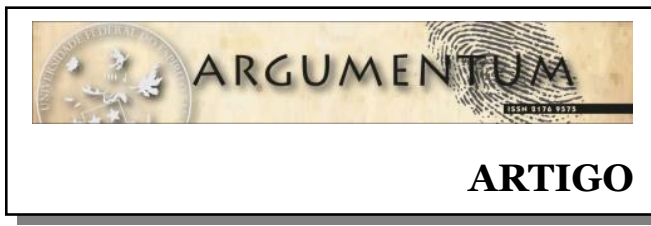

\title{
O papel do Estado nas expropriações: os impactos do Complexo de Suape (PE)
}

\author{
The Role of the State in expropriations: the case of the Suape Complex (PE) \\ Rebeca Gomes de Oliveira SILVA* \\ Maria das Graças e SILVA**
}

\begin{abstract}
Resumo: O presente ensaio visa expor os resultados de um estudo sobre as expropriações de comunidades tradicionais no Brasil, com destaque para o papel do Estado nesses processos, tomando como referência empírica o Complexo Industrial e Portuário de Suape em Pernambuco. A categoria expropriação, originalmente exposta por Marx, tem chamado a atenção de pesquisadores dada a sua força heurística, contribuindo para o desvelamento de processos de migrações forçadas como parte das contratendências engendradas pelo capital para escapar à sua crise estrutural. Neste ensaio ${ }^{1}$ destacamos os mecanismos pelos quais o Estado contribui para as expropriações violentas do produtor direto dos seus meios de produzir. Trata-se de pesquisa bibliográfica e documental. O processo investigativo nos evidenciou que o Estado atua, historicamente, na garantia das expropriações das comunidades que possuem uma troca metabólica fundada no autoconsumo, expropriações estas que se mantêm e se aprofundam no capitalismo contemporâneo desenvolvendo múltiplas formas de violência.
\end{abstract}

Palavras-chave: Expropriação. Estado. Comunidades tradicionais. Capitalismo contemporâneo.

Abstract: This present the results of a study on the expropriation of traditional communities in Brazil, highlighting the role of the State in these processes and takes the Suape Industrial and Port Complex in Pernambuco as its empirical reference. Expropriation, originally exposed by Marx, has attracted the attention of researchers because of their heuristic strength, contributing to the unveiling of forced migration processes as part of the countertendencies engendered by capital to escape its structural crisis. In this essay we highlight the mechanisms by which the State contributes to the violent

\footnotetext{
* Assistente Social. Mestranda em Serviço Social pelo Programa de Pós-Graduação em Serviço Social da Universidade Federal de Pernambuco (UFPE, Recife, Brasil). Av. Prof. Moraes Rego, 1235, Cidade Universitária, CEP.: 50670-901. Com financiamento do Conselho Nacional de Desenvolvimento Científico e Tecnológico (CNPq). ORC ID: <https://orcid.org/oooo-0oo1-6013-3153>. E-mail: $<$ rebecagomes.gomes@mail.com>.

** Doutora em Serviço Social. Docente do Programa de Pós-Graduação em Serviço Social da Universidade Federal de Pernambuco (UFPE, Recife, Brasil). Av. Prof. Moraes Rego, 1235, Cidade Universitária, CEP.: 50670-901. ORC ID: <https://orcid.org/oooo-0002-6583-831X>. E-mail: <gracita.pe@gmail.com>.
}

(c)) EY (c) A(s) Autora(s)/O(s) Autor(es). 2018 Acesso Aberto Esta obra está licenciada sob os termos da Licença Creative Commons Atribuição 4.0 Internacional (https://creativecommons.org/licenses/by/4.o/deed.pt_BR), que permite copiar e redistribuir o material em qualquer suporte ou formato, bem como adaptar, transformar e criar a partir deste material para qualquer fim, mesmo que comercial. O licenciante não pode revogar estes direitos desde que você respeite os termos da licença.

${ }^{1}$ Esse artigo apresenta discussões encaminhadas no processo de escrita da dissertação de mestrado, no Programa de Pós-graduação em Serviço Social, da Universidade Federal de Pernambuco. Em nossa discussão, discutimos os mecanismos e as estratégias, políticas e ideológicas, utilizadas pelo Estado, com vistas a garantir as expropriações no Complexo de Suape.

Argum., Vitória, v. 11, n. 2, p. 122-137, maio/ago. 2019. |ISSN 2176-9575 
expropriation from the direct producer of their means of production. This is a bibliographical and documentary research. The investigative process has shown us that the state has acted historically in guaranteeing the expropriation of communities that have a metabolic exchange based on selfconsumption, expropriations that are maintained and deepened in contemporary capitalism by developing multiple forms of violence.

Keywords: Expropriation. State. Traditional communities. Contemporary capitalism.

Submetido em: 31/3/2019. Aceito em: 18/6/2019.

\section{INTRODUÇÃO}

A

s relações sociais do capital demandam, para sua afirmação, formas sociais específicas que lhes deem garantia de sua permanência. Essa condição mantémse desde a formação original do sistema capitalista, momento em que tem centralidade a expropriação do produtor direto dos seus meios de produção e de subsistência e sua concentração e centralização nas mãos dos capitalistas, produzindose, assim, o trabalhador livre - posto que dispõe tão somente de sua força de trabalho como fonte de sua sobrevivência - (MARX, 2013).

Essa separação radical, como nos lembra Marx, contou historicamente com o apoio do Estado, seja no que diz respeito ao uso direto de métodos violentos de expropriação ou através de legislações, igualmente violentas. Portanto, para entender o capitalismo - e as manifestações contemporâneas das expropriações - faz-se essencial demarcar o papel do Estado moderno, visto que este tornou-se a expressão política do capital, condicionando as relações entre as classes sociais e o modo como se deve proceder para viabilizar a economia de mercado (MÉSZÁROS, 2015).

Partimos do suposto de que as expropriações não se limitam à gênese da acumulação capitalista; elas permanecem na cena contemporânea e, em tempos de crise estrutural do capital, realizam-se de forma cada vez mais devastadora. Neste contexto, o Estado passa a comportar-se enquanto estrutura corretiva, visando controlar as contradições do sistema capitalista, intensificando sua atuação no sentido de manter as expropriações e de expandi-las (MÉSZÁROS, 2015).

Este trabalho propõe uma reflexão sobre as expropriações no chamado neodesenvolvimentismo, caracterizado, segundo Boito Jr, (2016), como um período dirigido por uma frente política policlassista com o objetivo de garantir o crescimento econômico, tendo o Estado brasileiro forte atuação no processo de expansão do capital, como impulsionador e patrocinador do desenvolvimento, adotando medidas anticíclicas ante a crise de acumulação. Tendo como lastro o boom das commodities o Estado brasileiro investe em grandes projetos de desenvolvimento, voltados a baratear os custos da produção e circulação de mercadorias, dotando-as de maior competitividade no mercado mundial, fato esse que implicou um conjunto de investimentos públicos na área de produção de energia, irrigação, transporte e comunicação (SILVA, 2018).

O Complexo Industrial e Portuário de Suape (CIPS), localizado no litoral sul de Pernambuco, teve sua expansão nesse período, fato que o levou a ser então

Argum., Vitória, v. 11, n. 2, p. 122-137, maio/ago. 2019. |ISSN 2176-9575 
considerado a joia da coroa, dado o ritmo de sua expansão (acima do crescimento econômico do país) e a sua transformação em polo naval e petroquímico ${ }^{2}$. Para efeito deste ensaio, interessa-nos refletir sobre os processos violentos de expropriações das comunidades tradicionais que viviam (em) nessa localidade, situando-os como parte dos contraditórios processos que definem a acumulação no período de crise estrutural do capital.

Pretende-se, portanto, neste breve artigo, discutir sobre a atualidade da categoria expropriação, tomando-a a partir das análises de Marx e de autores contemporâneos, a exemplo de Massimo Angelis e Virgínia Fontes. Busca-se, também, o aporte de autores clássicos e contemporâneos para uma compreensão dos mecanismos e estratégias pelas quais o Estado opera no interior da acumulação, especialmente na garantia da propriedade privada sobre os meios de produção e na constituição do trabalhador livre, plena e diretamente subordinado ao mercado. O objetivo é refletir sobre o papel do Estado na garantia das expropriações das comunidades tradicionais ${ }^{3}$, trazendo elementos que revelam esse fenômeno na realidade brasileira, com destaque para as comunidades impactadas pelo CIPS.

\section{O PAPEL DO ESTADO MODERNO NAS EXPROPRIAÇÕES: VIOLÊNCIA COMO POTÊNCIA ECONÔMICA}

No capítulo XXIV, do Livro I de O Capital, o qual trata sobre $A$ assim chamada acumulação primitiva, Karl Marx analisa o processo histórico que determinou a configuração das relações de capital. Para chegar à versão final dessa análise, Marx desenvolveu textos que traziam, embrionariamente, os fundamentos da acumulação primitiva do capital, principalmente os elementos presentes nos debates sobre a lei do furto da madeira, de 1842, e os Grundrisse, escritos entre 1857 e 1858 . Marx é movido, dentre outras razões, pela necessidade de combater uma concepção burguesa e simplista do capital (enquanto estoque) e das relações de propriedade, tomadas idilicamente, onde "[...] haveria, por um lado, uma elite laboriosa, inteligente e, sobretudo, parcimoniosa, e, por outro, uma súcia de vadios a dissipar tudo o que tinha e ainda mais" (MARX, 2013, p. 785). O que esse teórico afirma como capital é a sua caracterização enquanto relação de classe e irrefutável atuação do Estado através, principalmente, do recurso à violência.

A acumulação primitiva para Marx foi “[...] uma acumulação que não é resultado do modo de produção capitalista, mas seu ponto de partida [...]” (MARX, 2013, p. 785), processo histórico que significou a ascensão do capitalismo sobre o sistema feudal. $\mathrm{O}$

\footnotetext{
${ }^{2}$ Segundo o Documento Suape - Redenção e Contradição, a riqueza gerada em Suape, nos anos de 2009 e 2010, responde por, aproximadamente, 21\% do Produto Interno Bruto (PIB) de Pernambuco, representando um montante de investimentos da ordem de 22 bilhões de dólares (JORNAL DO COMMERCIO, 2011).

3 Por comunidades tradicionais entende-se aqueles grupos de pessoas que detêm seus meios de produção e que têm na relação com a natureza e demais recursos naturais sua fonte de sobrevivência, possuindo uma troca metabólica fundada no autoconsumo. Esta forma de sociabilidade e de propriedade se contrapõe ao modo de produção capitalista fundado exclusivamente, pela troca, em que todas as relações são pela via do mercado (FONTES, 2010).
} 
elemento fundamental desse processo é a separação dos produtores diretos de suas terras, de seus meios de produção e de subsistência e a propriedade privada desses meios pelos capitalistas, o que Marx caracteriza como expropriação.

\begin{abstract}
O processo que cria a relação capitalista não pode ser senão o processo de separação entre trabalhador e a propriedade das condições de realização de seu trabalho, processo que, por um lado, transforma em capital os meios sociais de subsistência e de produção e, por outro, converte os produtores diretos em trabalhadores assalariados (MARX, 2013, p. 786).
\end{abstract}

Para que a terra, os meios de produção e de subsistência se transformassem em capital, foi necessário que duas espécies diferentes de possuidores se defrontassem e estabelecessem contato: de um lado, os que passaram a ser os possuidores de dinheiro, da terra, dos meios de produção e de subsistência, que buscam valorizar a quantia de valor de que dispõem a partir da compra da força de trabalho; de outro, trabalhadores "livres", vendedores de sua própria força de trabalho, tudo que lhes restou depois de terem sido expropriados de todas as garantias de sua existência (MARX, 2013). Essa polarização é essencial para a valorização do capital.

A separação dos produtores diretos dos seus meios de produção e a consequente polarização entre trabalhadores e capitalistas é um ponto central da acumulação primitiva. Angelis (2018), salienta que a expropriação é uma categoria elementar da crítica de Marx à economia política. Os produtores diretos constituíam um obstáculo à acumulação primitiva, por isso diferentes mecanismos foram implementados, principalmente através do Estado, para expropriar esses trabalhadores de suas terras, de seus meios de produção e de subsistência. A expropriação da terra, antes pertencente às comunidades camponesas, é “[...] a base de todo processo" (MARX, 2013, p. 787-788). Segundo Pazello (2016, p. 8o), “[...] este é o elemento mais sensível da explicação marxiana, já que apresenta o significado da separação entre trabalhador e meios de trabalho via meio de subsistência básico, nodal para qualquer comunidade tradicional, qual seja, a territorialidade". Massas de camponeses que subsistiam materialmente através do uso produtivo da terra foram despojadas de suas terras, de suas garantias de existência, sendo forçadas a procurar alternativa no mercado capitalista em ascensão.

Diferentemente da ideia idílica defendida pela economia política, essas expropriações materializaram-se, sobretudo, através da violência, sendo esta uma potência econômica. Nas palavras de Marx (2013, p. 786) “[...] o papel principal é desempenhado pela conquista, a subjugação, o assassínio para roubar, em suma, a violência”. De acordo com Pazello (2016, p. 80), "[...] a desterritorialização do produtor rural não é consequência da racionalidade econômica do capital, vista em seu formato pacífico, mas decorrência de seus sangramentos pressupostos”.

[...] esses recém-libertados só se converteram em vendedores de si mesmos depois de lhes terem sido roubados todos os meios de produção, assim como todas as garantias de sua existência que as velhas instituições feudais lhes ofereciam. E a história dessas expropriações está gravada nos anais da humanidade com traços de sangue e fogo (MARX, 2013, p. 787). 
Marx descreve os processos de expropriação que foram marcados por diversas formas de violência e roubo sobre as populações. Esses processos, na Europa, tiveram início em fins do século XV e primeiras décadas do século XVI, mas se estenderam até o século XIX. O primeiro grande processo de expropriação foi a expulsão dos pequenos camponeses de sua terra comunal com a dissolução dos séquitos feudais (MARX, 2013).

O papel das legislações na expropriação das comunidades camponesas é evidenciado por Marx nos textos sobre a lei referente ao furto da madeira. Ainda no contexto da transição do feudalismo para o capitalismo, no oeste da Alemanha, na província de Reno, uma proposta de lei submetida à Dieta Renana considerava a coleta de madeira realizada pela população expropriada camponesa, até então considerado um direito consuetudinário, como furto (MARX, 2017). A lei visava garantir o direito de propriedade da terra e de tudo que sobre ela existisse aos proprietários florestais cujas terras foram adquiridas mediante a expropriação das comunidades que ali habitavam, consideradas terras comuns e que em suas práticas coletavam madeira para utilidades diversas. Entretanto, com a propriedade privada da terra e com a mercantilização da madeira, os camponeses expropriados só poderiam ter acesso a ela através da compra. E caso violassem essa lei, furtando madeira alheia, deveriam pagar uma multa ou realizar serviços para o proprietário florestal (MARX, 2017).

Nestes termos, o direito de propriedade sobrepôs-se ao direito de subsistência, a sociedade capitalista em formação passou a penalizar as práticas consuetudinárias do direito ao uso da madeira (BENSAÏD, 2017). Marx adverte que, com a provação dessa lei, “[...] o interesse privado é esperto o suficiente para extrapolar essa consequência no sentido de fazer com que sua forma mais limitada e pobre se torne o limite e a regra da ação do Estado" (MARX, 2017, p. 98) e afirma que "[...] todos os órgãos do Estado se convertem em orelhas, olhos, braços e pernas que o interesse do proprietário florestal usa para escutar, espiar, estimar, proteger agarrar e correr" (p. 104).

\footnotetext{
Todos, porém, utilizaram o poder do Estado, a violência concentrada e organizada da sociedade, para ativar artificialmente o processo de transformação do modo feudal de produção em capitalista e para abreviar a transição. A violência é a parteira de toda velha sociedade que está prenhe de uma nova. Ela mesma é uma potência econômica (MARX, 2013, p. 821).
}

Outro "[...] novo e terrível impulso ao processo de expropriação violenta das massas populares [...]" (MARX, 2013, p. 792), no século XVI, foi dado pela Reforma Protestante, com o roubo colossal dos bens da Igreja Católica. Havia uma lei que garantia a propriedade para os camponeses empobrecidos que passavam a viver nos conventos, através do acesso a uma parte dos dízimos da igreja. Todavia, essa propriedade foi "[...] tacitamente confiscada [...]” (MARX, 2013, p. 793), com a supressão dos monastérios e conventos, convertendo os camponeses em proletariado.

Nas últimas décadas do século XVII e no decorrer do século XVIII, um novo processo de expropriação atinge os yeomanry, "[...] uma classe de camponeses independentes [...]"que era "[...] mais numerosa que a classe dos arrendatários" (MARX, 2013, p. 794). Essa classe, nos anos de 1750, havia desaparecido, juntamente com o último resquício 
da propriedade comunal dos lavradores. Ainda no século XVII, Marx destaca o processo de expropriação de domínios estatais, pela Revolução Gloriosa, "[...] que, até então, era realizado apenas em proporções modestas" (MARX, 2013, p. 795).

Já no século XIX ocorre o "[...] grande processo de expropriação que privou os lavradores da terra [...]" (MARX, 2013, p. 80o), intitulada como clearing of estates, ou seja, o "[...] clareamento das propriedades rurais, o que significa, na verdade, varrê-las de seres humanos [...]” (MARX, 2013, p. 80o), fazendo com que os pequenos trabalhadores rurais já não encontrassem espaço necessário e nem condições mínimas para permanecer em suas terras

O que interessa, aqui, evidenciar, é que esses processos de expropriação guardam uma diferença crucial entre si: Marx (2013) afirma que no século XV e XVI as expropriações se efetuaram unicamente por meio de atos individuais de violência contra os quais a legislação lutou durante 150 anos. Contudo, com o avanço do sistema capitalista, no século XVIII em diante, "[...] a própria lei se torna, agora, o veículo do roubo das terras do povo" (MARX, 2013, p. 796), em outras palavras, é o próprio Estado burguês seu principal baluarte.

Neste sentido, a violência extraeconômica e a força do Estado fundamentaram a "[...] criação do proletariado inteiramente livre, a disciplina sanguinária que os transforma em assalariados, a sórdida ação do Estado, que, por meios policiais, eleva o grau de exploração do trabalhador e, com ele, a acumulação do capital” (MARX, 2013, p. 813).

\begin{abstract}
A violência extraeconômica surge como componente central da gênese histórica da produção capitalista. Por evidente que seja a coação silenciosa da economia sobre a classe trabalhadora, ou melhor, a violência econômica interiorizada no processo capitalista de produção como 'lei natural' (Marx, 2013[1867], p. 808-809), a dimensão coersiva e coercitiva do Estado para as condições gerais de produção é ineliminável do modo de produção capitalista (CASTELO; RIBEIRO; LIMA, 2018, p. 269).
\end{abstract}

Apesar de ser uma condição indispensável, a expropriação das terras não era suficiente para formar trabalhadores inteiramente livres, era necessário acrescentar à tal expropriação "[...] leis grotescas e terroristas [...]" (MARX, 2013, p. 808) que forçassem esses trabalhadores a submeterem-se à nova lógica de trabalho. A expropriação violenta dos produtores diretos, os quais foram arrancados de seus modos de vida, fez com que muitos deles não conseguissem se adequar à disciplina imposta pela nova dinâmica do sistema capitalista e, por consequência, como afirma Marx (2013), "[...] converteram-se massivamente em mendigos, assaltantes, vagabundos, em parte por predisposição, mas na maioria dos casos por força das circunstancias" (MARX, 2013, p. 805-806).

O surgimento da "[...] legislação sanguinária contra a vagabundagem [...]"4 (MARX, 2013, p. 806), que impunha castigo para quem não se submetesse à lógica capitalista que se fortalecia, é pura expressão de violência extraeconômica, conduzida pelas mãos do Estado. Marx assinala que

${ }^{4}$ A Lei dos Pobres é emblemática deste momento. 
[...] a população rural, depois de ter sua terra violentamente expropriada, sendo dela expulsa e entregue à vagabundagem, viu-se obrigada a se submeter, por meio de leis grotescas e terroristas, e por força de açoites, ferros e brasa e torturas, a uma disciplina necessária ao sistema de trabalho assalariado (MARX, 2013, p. 8o8).

Assim, o Estado, enquanto produto de uma determinada fase do desenvolvimento social, marcada pelo surgimento da propriedade privada, volta-se, agora, para garantir a dominação da burguesia, respaldar e defender o processo da acumulação. Por sua vez, as diferentes formas de violência por meio das quais se separou o produtor direto de suas condições de existência, converteram o Estado em uma grande força econômica. O Estado determina as condições econômicas e sociais desse processo e engendra medidas para que sua atuação não seja questionada, declarando como legal apenas aquelas demandas da sociedade que não contrariam a garantia da propriedade privada, estando, essencialmente, do lado de quem detém poder econômico.

\section{A PERMANÊNCIA DAS EXPROPRIAÇÕES E O PAPEL DO ESTADO NO CAPITALISMO CONTEMPORÂNEO}

A categoria expropriação evidencia que a referência marxiana sobre a acumulação capitalista transpõe sua natureza puramente econômica e desborda para as relações sociais, manifestando-se como o modo de ser do capital. Assim, as expropriações se fazem presentes tanto na acumulação originária, quanto na acumulação plenamente capitalista, principalmente em sua fase madura. Marx afirma que "[...] tão logo a produção capitalista esteja de pé, ela não apenas conserva essa separação, mas a reproduz em escala cada vez maior" (MARX, 2013, p. 786). Portanto, entender a expropriação no contexto da acumulação do capital revela a continuidade e a centralidade dessa categoria na dinâmica do capital ${ }^{5}$.

Na busca por retomar o debate das expropriações e a afirmação de sua inequívoca atualidade, Fontes (2010) lembra que a existência de trabalhadores livres é a base social primordial que constitui a relação capital e trabalho, a qual permite a acumulação

\footnotetext{
5 Há um amplo debate sobre o caráter histórico ou transhistórico da acumulação primitiva, marcadamente dos processos de expropriação, enquanto separação do trabalhador dos meios de trabalho e sua conversão em trabalhador livre. Na contemporaneidade dois autores vêm se destacando nessa discussão: o David Harvey (2014) e a Virgínia Fontes (2010). O Harvey em sua obra o Novo Imperialismo debate o renascimento modificado da acumulação primitiva na contemporaneidade, nomeado de acumulação por espoliação. O autor dialoga com a tese da Rosa Luxemburgo (1988), a qual defende que para o sistema capitalista existir necessita permanentemente de algo externo a si para que, consequentemente, seja inserido na lógica capitalista. Com base nisso, Harvey discute a dialética das dimensões internas e externas e afirma que na atual fase do capitalismo se tem produzido novas externalidades. Já a Virgínia Fontes considera que as expropriações, enquanto processo elementar do modo de ser do capital, que garante a base social do capital (a produção de trabalhadores livres) e os recursos necessários para garantir a acumulação, permanece desde a acumulação primitiva. Desse modo, diferentemente de Harvey, Fontes evidencia que na contemporaneidade é difícil afirmar que há algo externo ao capital, afinal, tudo, em alguma medida, está incorporado, mesmo que de maneira desigual, pois o capital tem a tendência permanente a tudo englobar.
}

Argum., Vitória, v. 11, n. 2, p. 122-137, maio/ago. 2019. |ISSN 2176-9575 
ampliada de capital. As expropriações, portanto, “[...] constituem um processo permanente, condição da constituição e expansão da base social capitalista e que, longe de se estabilizar, aprofunda-se e generaliza-se com a expansão capitalista" (FONTES, 2010, p.45).

\begin{abstract}
A condição fundamental para transformar o conjunto da existência social numa forma subordinada ao capital é a expropriação dos trabalhadores e sua separação das condições (ou recursos) sociais de produção, que corresponde a um processo histórico ao qual se superpõe, na atualidade, a exasperação dessas expropriações, através de uma disponibilização crescente da população mundial ao capital (FONTES, 2010, p. 42).
\end{abstract}

As expropriações, portanto, acompanham a história do desenvolvimento capitalista. A expropriação primitiva, que separa os produtores diretos de sua base fundiária, não se limita à formação do sistema capitalista, ela se reproduz em escala sempre crescente, conduzindo para a supressão não só das terras, mas também das condições de existência desses produtores (FONTES, 2010). Há uma incidência e um aprofundamento das expropriações primárias no capitalismo contemporâneo, comunidades tradicionais continuam a ser expropriadas de seus territórios, de seus modos de vida e dos recursos naturais indispensáveis à sua reprodução.

A busca desenfreada pela acumulação perpétua do capital resulta em constantes e perversas expropriações. Todavia, dadas as estratégias capital-burguesas para o enfrentamento de sua crise estrutural, estas tendências tendem à exponenciação ${ }^{6}$. Sob o comando do capital financeiro ${ }^{7}$, os excedentes de capitais em busca de valorização dirigem-se tanto a atividades não diretamente inseridas no circuito mercantil, subordinando-as (e, com isso, alargando o processo de mercantilização), quanto invadem áreas ou territórios, avançam sobre os recursos naturais, sobretudo na periferia do sistema. Essa dinâmica se afirma através de diversificados mecanismos, seja a intensificação da atividade extrativista (mineral, vegetal, etc.) cujo fim último é alimentar o circuito da descartabilidade, seja pela exportação, para os países periféricos, de capitais que demandam uso intensivo de recursos naturais (água, energia, grandes extensões de terra) ou, ainda, de atividades que são de natureza essencialmente poluente; fato é que, por tais vias, promove-se uma divisão internacional dos custos ambientais que penaliza a periferia (e nela as regiões mais pobres). Expulsam-se as populações de seus territórios, lançando-as na superpopulação relativa latente (ou diretamente no pauperismo), apropriando-se dos bens de uso comum, de seu conhecimento em nome do progresso e da riqueza social.

E o Estado cumpre papel decisivo neste processo. Não por acaso, lembra Mészáros (2015), "[...] a crise estrutural de nossa época ativa a demanda por um envolvimento cada vez mais direto do Estado na sobrevivência contínua do sistema” (MÉSZÁROS,

\footnotetext{
6 Segundo Mészáros (2011), o sistema capitalista vive desde a década de 1970 uma crise sem precedentes, uma crise estrutural do capital. Não se trata de uma crise do sistema capitalista estritamente, mas uma crise do capital, de seus mecanismos civilizatórios.

7 Diante da dificuldade de valorização do capital investido na produção as finanças passaram a prevalecer. Em sua aparência de dinheiro que gera dinheiro, D-D', o capital financeiro esconde a intensificação acelerada do mais-valor que se dá por meio da produção, D-d-m-d-D' (FONTES, 2010).
}

Argum., Vitória, v. 11, n. 2, p. 122-137, maio/ago. 2019. |ISSN 2176-9575 
2015, p. 27). Para este autor, o Estado moderno caracteriza-se como única estrutura que garante os objetivos do capital, que responde às necessidades que não podem ser diretamente resolvidas pelo próprio capital.

As formas estatais do sistema capitalista sempre se caracterizaram enquanto meios de manutenção e fortalecimento dos imperativos materiais da expansão sociometabólica do capital. Para Mészáros (2015), a lei no sistema capitalista é a "[...] lei do mais forte [...]” (MÉSZÁROS, 2015, p. 18), a lei de quem detém os recursos sociais de produção, que é legitimada pelo Estado. Contudo, esse autor salienta um aspecto do Estado que está para além da lei e do direito: a sua destrutiva ilegalidade que se torna "[...] regra recorrente em períodos de grandes crises" (MÉSZÁROS, 2015, p. 47). A violência, portanto, é parte desse processo, sendo uma característica do modo de ser do capital.

\title{
4 O BRASIL E O COMPLEXO DE SUAPE: A ATUAÇÃO DO ESTADO NAS EXPROPRIAÇÕES
}

As expropriações no contexto da América Latina possuem particularidades marcadas pelo período colonial. No processo da acumulação primitiva o subcontinente abasteceu a metrópole de recursos naturais, impulsionando a acumulação de capitais na Europa, enquanto consolidava sua condição de satélite do desenvolvimento capitalista. Assim, o roubo, a pilhagem e o genocídio dos povos originários foram as marcas presentes em sua formação e que perduram até os nossos dias. Desse modo, o Brasil possui historicamente, como base de sua economia, a expropriação dos recursos naturais e a exploração força de trabalho, visando atender a demanda do mercado externo. Segundo Prado Júnior (1991), em sua análise sobre a formação brasileira,

\begin{abstract}
Se vamos à essência da nossa formação veremos que na realidade nos constituímos para fornecer açúcar, tabaco, alguns outros gêneros; mais tarde ouro, diamante; depois algodão e em seguida café, para o comércio europeu. Nada mais que isto. É com tal objetivo, objetivo exterior, voltado para fora do país e sem atenção a considerações que não fossem o interesse daquele comércio, que se organizarão a sociedade e a economia brasileira (PRADO JÚNIOR, 1991, p. 31).
\end{abstract}

Nestes termos, a história do desenvolvimento do capitalismo no Brasil expõe a dependência como um traço essencial. Segundo Castelo (2016, p. 6o), ao ingressar no século XXI, o contexto brasileiro é de "[...] reafirmação e a consolidação de uma nova etapa do capitalismo dependente” (CASTELO, 2016, p. 6o). Neste período, o Brasil teve um crescimento econômico fomentado pelo boom das Commodities no cenário internacional $^{8}$. Nesse mesmo período a exportação de produtos manufaturados brasileiros caiu de $55 \%$ para $44 \%$, enquanto que a exportação de matérias-primas subiu de $28 \%$ para $41 \%$ (ANDERSON, 2011). Esse fato é resultado da forte valorização dos

8 Fontes (2010) destaca que esse momento de ampliação do desenvolvimento se deu, também, pela exportação de capitais como investimento estrangeiro direto (IDE) saindo do Brasil.

Argum., Vitória, v. 11, n. 2, p. 122-137, maio/ago. 2019. |ISSN 2176-9575 
preços internacionais das Commodities, período conhecido como superciclo das Commodities (2003-2011) ${ }^{9}$ (BLACK, 2015).

O Brasil aproveitou o boom das commodities para inaugurar uma nova agenda políticoeconômico-social, o chamado neodesenvolvimentismo. Esse ideário evidenciou a necessidade da classe dominante brasileira assimilar a classe trabalhadora no cenário político, com o intuito de formar uma frente política ampla que possibilitasse o desenvolvimento do capitalismo brasileiro (BOITO JR, 2016) projeto, que beneficia, sobretudo, o capital financeiro, o setor da construção civil além do grande capital agrário, atribuiu ao Estado o papel de fomentador da economia brasileira nas condições do mercado mundializado, impulsionando a expansão de capitais, através de megaprojetos, pautado nas grandes obras. Caracteriza-se como um Estado regulador, apto a realizar reformas para que "[...] tudo mude para permanecer o mesmo [...]" (CASTELO, 2016, p. 48) e atua também como Estado- investidor ou como Estadofinanciador (ALVES, 2016), o qual teve no Programa de Aceleração do Crescimento (PAC), criado em 2007, seu grande expoente (BRASIL, 2007). O Estado-financiador estrutura-se como meio "[...] capaz de financiar e constituir grandes corporações de capital privado nacional, com capacidade competitiva no mercado mundial [...]" (ALVES, 2016, p. 107), contando com a direta participação do Banco Nacional de Desenvolvimento Econômico e Social (BNDES), o qual se destacou, realizando operações de financiamento direto e/ou indireto para a concentração ou centralização dos capitais nacionais.

A expansão do CIPS foi um dos símbolos de desenvolvimento desta nova era. Iniciado em 1973, com a edição do Decreto Estadual no 2.845, e posteriormente com o Decreto Federal no 82899/78, o CIPS vem produzindo alterações abruptas, tanto no meio físico natural, quanto no modo de vida das comunidades existentes no território: são 13.500 hectares atuais, composto por 27 engenhos $^{10}$, terras de agricultores, pescadores no litoral sul de Pernambuco (MORETTI; COX, 2016)". Já em 1977, o Estado de Pernambuco desapropriou 4.985 hectares da Cooperativa Agrícola Tiriri (terras de Reforma Agrária), para instalar esse Complexo, processo que continua até hoje.

\footnotetext{
$9 \mathrm{O}$ ciclo de forte alta dos preços das commodities se deu pelo chamado feito China e também, com menos destaque, pelo fluxo de capital financeiro dos Estados Unidos para o Brasil. Entre os anos 1989 e 2012, a China emergiu como uma grande potência econômica mundial.

${ }^{10}$ No passado, a região onde hoje está instalado o Complexo de Suape era ocupada por engenhos vinculados à atividade sucroalcooleira. Entretanto, devido à falência desse setor, a terra pertencente à produção canavial foi destinada aos trabalhadores ligados à Cooperativa Agrícola Tiriri, formada por antigos trabalhadores das usinas, essa ação foi realizada pelo Instituto de Nacional de Colonização e Reforma Agrária (INCRA), em 1973. Essa cooperativa passou, então, a possuir o direito de compra e venda dessas terras. Assim, em 1980, a Cooperativa Tiriri vendeu suas terras à Empresa Suape. Um Termo de Convênio foi assinado entre a Cooperativa e a Empresa, o qual firmava o dever da empresa em conduzir os moradores para outras áreas ou o pagamento de indenizações pelas terras e pelas benfeitorias, fato que não foi cumprido plenamente (SOLÁ PEREZ, 2016).

${ }_{11}$ Através da Lei $\mathrm{n}^{0} \quad 7.763 / 78$, foi criada a Empresa Suape, de interesse público-privado, para administrar o CIPS, monitorar o desenvolvimento das obras e a implantação das atividades portuárias. CIPS é gerido pelo estado de Pernambuco, via Secretaria de Desenvolvimento Econômico do Estado de Pernambuco (SEDEC-PE).
} 
Propagado como o Eldorado Pernambucano, a locomotiva do estado, a menina dos olhos de Pernambuco, o CIPS ancorou-se num discurso de garantia de empregos, de progresso, de melhoria para todos, atraindo trabalhadores de diversos estados, regiões e de outros países. Os investimentos estatais tiveram grande papel em seu crescimento, principalmente do PAC I e II e do BNDES (BNDES 2012). Entre 2007 e 2010 o número de indústrias instaladas no CIPS saltou de 81 para 105 (RELATÓRIO, 2018).

Entretanto, o CIPS tem sido protagonista de um conjunto de expropriações ${ }^{12}$, com destacadas violações de direitos que vão desde promessas não cumpridas, retiradas e deslocamentos forçados de populações, impedimentos dos moradores de exercerem suas atividades extrativistas ou de plantio, negativa de acesso aos recursos pesqueiros e demais bens comuns até a repressão e ameaças, culminando em demolição de imóveis e derrubada de árvores, plantações, etc.: todas levadas a termo pela empresa Suape para dar lugar à expansão do CIPS $^{13}$ (SOLÁ PEREZ, 2016).

Também foi constatado desmatamento dos manguezais, poluição dos rios e do mar (COSTA, 2013), extinção de peixes, devido a dragagens - com a consequente diminuição da produção do pescado (marisco, peixes etc.) - além da dificuldade de navegabilidade dos pescadores em razão dos bloqueios do acesso ao mar e à água potável. As consequências imediatas foram a alteração da salinidade da água, o comprometimento do ecossistema e da vida de diversas espécies marinhas e a contaminação dos solos. Essas obras ocorreram em áreas de maior ocorrência de pesca, atingindo quem sobrevive dessa atividade (MORETTI; COX, 2016).

Em face da retirada dos trabalhadores de suas áreas foram anunciadas as indenizações por benfeitorias (casa construída ou plantações), como medidas compensatórias realizadas pela Empresa Suape. Com a implantação do PAC 2 (2011-2014) aproximadamente 1200 famílias foram indenizadas e tiveram que sair de suas terras, recebendo em torno de $\mathrm{R} \$ 93.000$ (SOLÁ PEREZ, 2016). Todavia, estas indenizações revelaram-se irrisórias ou não foram plenamente concretizadas. Diversas mobilizações ocorreram como meio de denunciar a violência para retirada das pessoas de suas terras e os valores irrisórios dessas indenizações (POSSEIROS, 2012). Na realidade, tais indenizações cumpriram um papel coercitivo, posto que se faziam acompanhar da imposição da empresa Suape: ou o trabalhador dela lançaria mão ou perderia tudo. Neste ato, se desconhece a posse, a função social da propriedade e vige tão somente a força econômica e política do capital.

\footnotetext{
${ }^{12}$ Solá Perez (2016) destaca três períodos de intensificação das expropriações: 1) 1977-1990, no começo da obra de implantação do Complexo; 2) 1900-2000, período de renovação da normatização dos portos; e, 3) 2007-2014, durante as obras financiadas pelo PAC e pelo BNDES, sendo esse último o período das maiores expropriações impulsionadas pelo Estado. Levantamento realizado em 2010 apurou que no território de 13.500 ha do CIPS há 6.800 famílias, habitando 27 engenhos da região (RELATÓRIO, 2018).

${ }_{13}$ A Ilha de Tatuoca, ocupada por cerca de 150 famílias de pescadores e pequenos agricultores, que lá viviam há mais de um século, desocupada para instalação da indústria naval é um dos exemplos desta afirmação.
} 
Esta tendência também se manifesta no licenciamento ambiental ${ }^{14}$, o qual não tem servido como mecanismo de discussão dos impactos socioambientais pela população afetada; ao contrário, tem se prestado como elemento de coerção e de cerceamento de direitos da população local ${ }^{15}$, dada a forma instrumental e autoritária com que vem implementando os Planos de Compensação e de Mitigação dos impactos negativos dos empreendimentos $^{16}$ (RELATÓRIO, 2016).

Com o aprofundamento da crise econômica e o escândalo de corrupção envolvendo a Petrobras ${ }^{17}$ o que se constata é o arrefecimento da atividade econômica do território. Moradores dessa localidade reclamam das dificuldades dos pequenos negócios se manterem, incentivando o aumento da informalidade. Casas antes ocupadas por operários que trabalharam com a construção do estaleiro estão agora desocupadas, tendo como última saída a venda das mesmas (JORNAL DO COMMERCIO, 2015).

Segundo o relatório publicado em 2018 pela Plataforma de Direitos Humanos, Econômico, Sociais, Culturais e Ambientais (DHESCA) ${ }^{18}$, intitulado Complexos Industriais e Violações de Direitos: o caso de Suape - Complexo Industrial Portuário Governador Eraldo Gueiros ${ }^{19}$, os impactos engendrados por esse projeto de desenvolvimento agudizaram a dependência das comunidades às relações mercantis. Em todos os 27 engenhos há depoimentos sobre os impactos do CIPS que envolvem violência, contaminação dos recursos naturais, adoecimento e expulsões. Vale ressaltar que essas violações vêm sendo diretamente implementadas pelo Estado, pois conduzidas pela Empresa Suape, ancorada em milícia própria para controlar o território.

\footnotetext{
${ }^{14}$ Segundo Loureiro (2010) "O licenciamento é um processo institucionalizado e atributo exclusivo do Estado que busca garantir certos padrões de desenvolvimento humano, social e de proteção e preservação ambiental, cujos critérios para a execução são definidos segundo motivações políticas e econômicas e paramentos oriundos do conhecimento científico" (LOUREIRO, 2010, p. 16).

${ }^{15 \mathrm{O}}$ licenciamento ambiental no Brasil, analisa a viabilidade dos empreendimentos em sua relação com os impactos socioambientais que podem gerar, recomenda medidas para mitigar seus impactos negativos e institui a compensação para os casos extremos ou inevitáveis.

${ }_{16}$ De acordo com os estudos referentes ao Programa de Comunicação Social e Interação com a Comunidade e ao Programa de Remanejamento, Relocação e Acompanhamento dos Moradores da Ilha de Tatuoca, como compensação e mitigação ao impactos da indústria naval, estes programas deveriam constituir um canal de comunicação direto com as comunidades. No entanto, este sequer foi posto em prática, as comunidades ficaram sabendo tardiamente dos impactos da instalação da indústria naval. Assim, a ameaça substituiu o diálogo e com a relocação das comunidades para o novo vilarejo, Nova Tatuoca, estas tiveram seus modos de vida totalmente descaracterizados (RELATÓRIO, 2016).

17 Os reflexos da Operação Lava Jato atingiram fortemente a Refinaria Abreu e Lima e o Estaleiro Atlântico Sul, nos quais mais de 45 mil trabalhadores foram dispensados, contradizendo todo o discurso da empregabilidade advinda com esses empreendimentos (CRISE..., 2015).

18 "A Plataforma de Direitos Humanos - Dhesca Brasil - é uma rede formada por 40 organizações da sociedade civil, que desenvolve ações de promoção e defesa dos direitos humanos, bem como na reparação de violações de direitos” (PLATAFORMA DHESCA BRASIL, 2018).

19 Também assim intitulado devido ao ex-governador de Pernambuco, Eraldo Gueiros Leite, que lançou a pedra fundamental de lançamento do Porto de Suape. (COMPLEXO INDUSTRIAL PORTUÁRIO DE SUAPE, 2016).
}

Argum., Vitória, v. 11, n. 2, p. 122-137, maio/ago. 2019. |ISSN 2176-9575 


\section{5 À GUISA DE CONCLUSÕES}

Decerto que a formação do capitalismo resultou em enormes violências. A separação do produtor direto de seus meios de existência foi imposta de modo coercitivo, visando lançá-lo livremente no mercado de trabalho em ascensão. O Estado estruturou-se, visando amparar os processos de expropriações, seja através da violência explícita ou de mecanismos legais igualmente violentos.

Assim, as expropriações não pertencem apenas à pré-história do capitalismo, mas seguem ocorrendo, pois constituem a base social do mundo burguês. Com a crise estrutural do capital vivemos o aprofundamento da submissão do trabalho ao capital, no qual sociedades inteiras vêm sendo inseridas plenamente na lógica mercantil, de forma que o Estado moderno passa a comportar-se enquanto estrutura corretiva, visando controlar as contradições do sistema, intensificando sua atuação no sentido de manter as expropriações e de alargá-las.

O Complexo de Suape expande-se nesse contexto, expropriando de modo violento as comunidades tradicionais que habitavam, historicamente, o território onde foi instalado: o faz, seja de maneira abrupta, rompendo os elos entre os produtores diretos e seus meios de vida (pescadores/as, agricultores/as, extrativistas), transformando-os nos mais novos integrantes da superpopulação relativa, seja atuando de maneira sistemática e intermitente no cerceamento das formas de produzir e de viver dessas comunidades, interditando-lhes o acesso às fontes de vida e de sua reprodução. Tais estratégias de expropriação vêm recheadas de discursos sedutores, mas também, e sobretudo, carregam as marcas da força, da coerção, do medo, cujo fim último é criar as condições plenas de domínio sobre o território.

Todavia, ao mesmo tempo em que o capital busca expandir-se, engendra a sua própria contradição. Com a intensificação dos processos expropriatórios, tais comunidades passaram a se organizar, reivindicando a permanência em seu território. A permanência dessas comunidades em seus territórios liga-se diretamente ao núcleo central da visão de Marx de uma sociedade humana na qual os "[...] produtores tenham acesso direto aos meios de produção” (ANGELIS, 2018, p. 8). Portanto, a luta das comunidades tradicionais vai para além da luta pela manutenção de seus modos de vida, de sua cultura: estrutura-se em uma luta na qual se reafirma a posse dos meios de existência, caracterizando-se como uma luta anticapitalista, opondo-se aos expropriadores e ao sistema que lhes dá sustentação.

\section{REFERÊNCIAS}

ALVES, G. A esfinge do neodesenvolvimentismo e a miséria do trabalho no Brasil (2003-2013). In: MACÁRIO, E.; VALE, E. S.; RODRIGUES JR, N.

Neodesenvolvimentismo, Trabalho e Questão Social. Fortaleza: Expressão Gráfica e Editora, 2016.

ANDERSON, P. O Brasil de Lula. Novos Estudos, n. 91, nov. 2011. 
ANDERSON, P. A esfinge do neodesenvolvimentismo e a miséria do trabalho no Brasil (2003-2013). In: MACÁRIO, E.; VALE, E. S.; RODRIGES JR, N.

Neodesenvolvimentismo, trabalho e Questão Social. Fortaleza: Expressão Gráfica e Editora, 2016.

ANGELIS, M. Marx e acumulação primitiva: o caráter contínuo das “vedações” do capital. O Comuneiro, Revista Eletrônica, n. 26, mar. 2018. Disponível em: <http://www.ocomuneiro.com/nr26_2_MassimodeAngelis.html>.

BENSAÏD, D. Os Despossuídos: Karl Marx, os ladrões de Madeira e o Direito dos Pobres. Apresentação. In: MARX, Karl. Os despossuídos: debates sobre a Lei referente ao furto da madeira. São Paulo: Boitempo, 2017.

BLACK, C. Preços de commoditites, termos de troca e crescimento econômico brasileiro nos anos 200o. Indic. Econ., FEE, Porto Alegre, v. 24, n. 3, 2015.

BNDES libera quase R 1 bi para Suape. Notícias, Ipojuca: Complexo Industrial Portuário de Suape, 23 out. 2012. Disponível em:

<http://www.suape.pe.gov.br/pt/noticias/39o-bndes-libera-quase-r-1-bi-para-suape>. Acesso em: 20 ago. 2018.

BOITO JR, A. A crise política do neodesenvolvimentismo e a instabilidade da democracia. Revista Crítica Marxista, n. 42, p. 155-162, 2016. Disponível em: https://www.ifch.unicamp.br/criticamarxista/arquivos_biblioteca/dossie2017_03_03_10 -57_34.pdf. Acesso em: 27 nov. 2017.

BRASIL. Ministério do Planejamento. Sobre o PAC. Programa de Aceleração do Crescimento (PAC), [2007] Disponível em: http://www.pac.gov.br/sobre-o-pac. Acesso em: 27 nov. 2017.

CASTELO, R. O canto da sereia: social-liberalismo, neodesenvolvimentismo e supremacia burguesa no capitalismo. In: MACÁRIO, E.; VALE, E. S.; RODRIGES JR, N. Neodesenvolvimentismo, Trabalho e Questão Social. Fortaleza: Expressão Gráfica e Editora, 2016.

CASTELO, R.; RIBEIRO, V.; LIMA, R. A violência como potência econômica: da acumulação primitiva ao novo imperialismo. In: BOSCHETTI, I. (org.). Expropriação e direitos no capitalismo. São Paulo: Cortez, 2018.

COMPLEXO INDUSTRIAL PORTUÁRIO DE SUAPE. Histórico. Ipojuca, 2016. Disponível em: http://www.suape.pe.gov.br/pt/institucional/historico-de-suape. Acesso em: 8 jan. 2019.

COSTA, Heitor Scalambrini. Suape fora da Lei. 20 nov. 2013. Disponível em: http://denunciapeloterritorio.blogspot.com/2013/11/suape-fora-da-lei.html. Acesso em: 20 ago. 2018 
CRISE em Suape provoca demissões em massa e fechamento de empresas. Bol vídeos, 8 jul. 2015. Disponível em: https://videos.bol.uol.com.br/video/crise-em-suapeprovoca-demissoes-em-massa-e-fechamento-de-empresas-04024E183562CCA95326. Acesso em: 26 ago. 2015.

FONTES, V. O Brasil e o Capital Imperialismo: teoria e história. Rio de Janeiro: UFRJ, 2010.

HARVEY, D. O Novo Imperialismo. São Paulo: Edições Loyola, 2014.

JORNAL DO COMMERCIO. Documento Suape 2011: Redenção e Contradição. Jornal do Commercio, 2011. Recife, 12 ago, 2011.

JORNAL DO COMMERCIO. Documento Suape 2015. Jornal do Commercio, 2015. Disponível em: http://especiais.jconline.ne1o.uol.com.br/documento-suape-2015/. Acesso em: 26 ago. 2015

LOUREIRO, C. F. B. (org). Gestão Ambiental e educação ambiental: caminhos e interfaces. Sinais Sociais, Rio de Janeiro, v. 5, n. 14, 2010.

LUXEMBURGO, R. A Acumulação do capital: contribuição ao estudo econômico do Imperialismo. São Paulo: Nova Cultural, 1988.

MARX, K. [1818-1883]. O Capital: crítica da economia política. Livro 1: o processo de produção do capital. Trad. Rubens Enderle. São Paulo: Boitempo, 2013.

MARX, K. Os Despossuídos: Debates sobre a Lei Referente ao Furto da Madeira. São Paulo, Boitempo, 2017.

MÉSZÁROS, I. A montanha que devemos conquistar. São Paulo: Boitempo, 2015.

MÉSZÁROS, I. Para além do capital: rumo a uma teoria da transição. São Paulo: Boitempo, 2011.

MORETTI, R; COX, M. Impactos ambientais ao longo da implantação e consolidação do Complexo Industrial de Suape (PE). Rev. Gaia Scientia, João Pessoa, v. 10, n. 1, 2016.

PAZELLO, R. P. Acumulação originária do capital e direito. Revista InSurgência, Brasília (DF), ano 2, v.2, n.1, 2016.

RELATÓRIO Complexos Industriais e Violações de Direitos: o caso de Suape Complexo Industrial Portuário Governador Eraldo Gueiros - Relatório da Missão de Investigação e Incidência. Curitiba: Plataforma DHESCA Brasil, 2018. Disponível em: $<$ https://fase.org.br/wp-content/uploads/2018/12/relatorio_suape_WEB_v3.pdf>. 
PERNAMBUCO. Governo do Estado. Lei n 7.763. Recife, 7 nov, 1978. Disponível: <http://www.suape.pe.gov.br/images/publicacoes/Leis/lei_n_7763_1978.pdf>.

PLATAFORMA DHESCA BRASIL. Quem somos. Curitiba, C2018. Disponível em: http:http://www.plataformadh.org.br/quem-somos/. Acesso em: 8 dez. 2018.

PRADO JR, C. Formação do Brasil contemporâneo. São Paulo: Brasiliense, 1991.

RELATÓRIO final PIBIC. O Programa de Comunicação e Interação com a Comunidade: os condicionantes sociais do licenciamento do Estaleiro Promar S. A. Recife: Universidade Federal de Pernambuco, 2016.

POSSEIROS protestam contra Suape, em Cabo de Santo Agostinho (PE). Setor de Comunicação da CPT NE II, Recife: Comissão Pastoral da Terra Nordeste II, 3 fev. 2012. Disponível em:

https://cptne2.org.br/index.php/publicacoes/noticias/noticias/3214-posseirosprotestam-contra-suape-em-cabo-de-santo-agostinho-pe. Acesso em: 29 jan. 2017.

SILVA, M. G. Desenvolvimento capitalista e megaprojetos: expropriações em tempos de mundialização do capital. In: MONDAINI, M. (org.). As antinomias do desenvolvimento: uma crítica aos megaprojetos no Brasil, Moçambique e Cabo Verde. Recife: Universidade Federal de Pernambuco, 2018.

SOLÁ PEREZ, M. R-existência dos camponeses/as do que hoje é Suape: justiça territorial, pós-desenvolvimento e descolonialidade pela vida. 2016. Tese (Doutorado em Geografia)-Universidade Federal de Pernambuco, Recife, 2016.

Rebeca Gomes de Oliveira SILVA Trabalhou na concepção e delineamento do artigo. Graduada em Serviço Social pela Universidade Federal de Pernambuco (UFPE) e mestranda no Programa de Pós-Graduação em Serviço Social da UFPE. Realiza pesquisa na área de questão ambiental e capitalismo contemporâneo.

Maria das Graças e SILVA Trabalhou na revisão crítica e aprovação da versão a ser publicada. Professora Associada da Universidade Federal de Pernambuco (UFPE), vinculado ao Centro de Ciências Sociais Aplicadas e ao Programa de Pós-Graduação em Serviço Social. Possui Graduação, mestrado e doutorado em Serviço Social pela UFPE. Tem atuado nos seguintes temas: Questão ambiental, conflitos socioambientais e capitalismo contemporâneo. 